\title{
Treating implicit trauma: a quasi- experimental study comparing the EMDR Therapy Standard Protocol with a 'Blind 2 Therapist' version within a trauma capacity building project in Northern Iraq
}

\author{
Derek Farrell ${ }^{1,2^{*}}$, Matthew D. Kiernan ${ }^{3,4}$, Ad de Jongh ${ }^{1,5,6,7,8}$, Paul William Miller ${ }^{9,10}$, Peter Bumke ${ }^{2}$, Salah Ahmad ${ }^{11}$, \\ Lorraine Knibbs ${ }^{1}$, Cordula Matthe ${ }^{1}$, Paul Keenan ${ }^{12}$ and Helga Matthe ${ }^{2}$
}

\begin{abstract}
Psychological trauma is a silent epidemic which presents as a global public health issue, often in the form of posttraumatic stress disorder (PTSD). Eye Movement Desensitisation and Reprocessing (EMDR) Therapy is an empirically supported treatment intervention for PTSD and has been used as part of trauma-capacity building, particularly in lowand middle-income countries (LMIC). For some survivor's, their trauma experiences cannot be spoken of: they may be alluded to, suggested and though not directly expressed. There are several factors as to why these implicit trauma experiences are 'unspoken', for example, when the trauma involves a deep-rooted sense of shame or guilt, a distorted sense of over-responsibility or when to speak of the trauma engenders fear of retribution, reprisal and consequence. This paper will explore the effectiveness of using two protocol variations of EMDR Therapy—standard versus a 'Blind 2 Therapist' protocol version as part of a quasi-experimental study which took place in Northern Iraq. The study contains two projects and subsequently tested several hypotheses regarding safety, effectiveness, efficiency and relevance of the 'Blind 2 Therapist' protocol within EMDR Therapy. Results indicated support for the B2T protocol intervention with various trauma populations including Yezidi survivors of Islamic State of Iraq and the Levant (ISIL)—also known as Daesh.
\end{abstract}

Keywords: EMDR, Trauma, Treatment, Shame, Retribution, Implicit, Standard Protocol, Blind 2 Therapist Protocol

\section{Introduction}

Emotional responses to an extreme event such as a serious accident, rape or natural disaster can include shock, denial, unpredictable emotions, flashbacks, strained relationships and even physical symptoms, for example, headaches, pain or nausea (Courtois and Ford 2009; Tol et al. 2013). One of the possible effects of exposure to a traumatic event is the development of post-traumatic stress disorder (PTSD). Carriere (2014) estimates that

\footnotetext{
* Correspondence: d.farrell@worc.ac.uk

${ }^{1}$ University of Worcester (UK), Worcester, UK

${ }^{2}$ Trauma Aid Germany, Duisburg, Germany

Full list of author information is available at the end of the article
}

globally, some 500 million suffer from PTSD-mainly women and children, describing it as a 'silent epidemic' and a 'global public health issue' that impacts upon physiology, neural circuits, genetics, emotions, world view, sense of purpose and our overall ability to socially adapt. If left untreated, PTSD has the potential to become more chronic and complicated (Chessen et al. 2011; Priebe et al. 2009). Figure 1 highlights an international perspective relating to the prevalence of PTSD.

One of the 'strongly recommended' treatments for PTSD is Eye Movement Desensitisation and Reprocessing (EMDR) Therapy (WHO 2013), a trans-diagnostic, integrative psychotherapy approach, which is intrinsically client-centred at 


\section{Prevelance of PTSD \%}

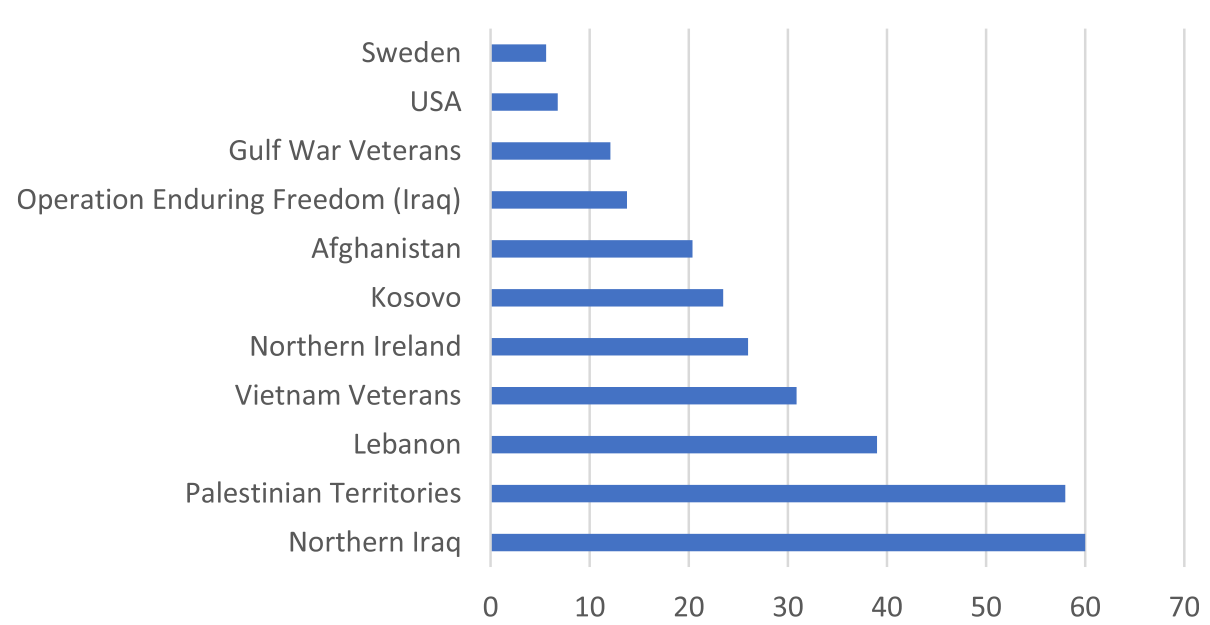

Fig. 1 International perspectives on the prevalence of post-traumatic stress disorder (PTSD)(Ahmad 2016; Arnberg et al. 2013; Bunting et al. 2012; Farhood et al. 2006, Farhood and Dimassi 2012; Gradus 2007; Kilpatrick et al. 2013; Qouta et al. 2003)

its core (Farrell 2016a, 2018). EMDR Therapy has been extensively researched, with proven effectiveness in the treatment of a wide range of symptoms due to adverse life experiences (Shapiro 2016, 2018). It utilises a theoretical framework known as adaptive information processing (AIP) - a meta-theory that focusses on pathogenic memories-the origin of many psychiatric symptoms relating to the formation and consolidation of implicit dysfunctional memories (Centonze et al. 2005; Hase et al. 2017).

EMDR Therapy has gained recognition throughout the world (WHO 2013; ISTSS 2018; Bisson et al. 2019); however, its integration into national mental health systems is varied particularly in low- to middle-income countries (LMIC). Within LIMC's, there are four compounding factors to consider: firstly, wide-ranging diversity in the availability of mental health service provision; secondly, insufficient mental health professionals to fully address the global burden of psychological trauma; thirdly, problems with access to suitably qualified, specialist trained and experienced mental health professionals in the field of psychological trauma; and fourthly, significant variation in quality of training, experience and competency of mental health professionals.

Over the last 20 years, the development of EMDR Therapy in LMIC has occurred in response to humanitarian activity or targeted trauma capacity building in response to natural or human disasters (Adúriz et al. 2009; Eichfeld et al. 2019; Farrell et al. 2011, Farrell and Keenan 2013, Farrell 2014; Fernandez et al. 2014; Gelbach and Davis 2007; Hasanovic 2016; Jarero et al. 2008; Konuk and Zat 2015; Matthess et al. 2019; Maxfield 2014; Mehrotra 2014; Shapiro 2012; Shapiro 2014a, 2014b; Silver et al. 2005).
One such trauma capacity building project was set up in response to the Islamic State of the Levant (ISIL) also known as Daesh. In June 2014, ISIL launched a military offensive in Syria and Northern Iraq. One of the ethnic and religious minorities that ISIL attacked were the Yezidi Community, carrying out a campaign of killing, massacre, hostage-taking, enslavement, sexual exploitation and rape (Byman 2016; Ceri et al. 2016; Mohammadi 2016). Cetorelli et al. (2017) estimated that 9900 Yezidi were either killed or captured in just a matter of days in August 2014. Yezidi women were raped and used as sex slaves to ISIL Jihadists. Some of the Yezidi woman survived and returned to their families and community; however, many are still missing (Mohammadi 2016; Womersley and Arikut-Treece 2019). Those that return recount narratives of unspeakable human rights violations including sexual, physical and psychological abuse (Nicolaus and Yuce 2017).

ISIL has been recognised by the United Nations as the perpetrators of genocide towards the Yezidi population (Dakhil et al. 2017). According to Mohammadi (2016), the Yezidi have faced genocide on over 70 occasions during the Ottoman Empire and highlights for the Yezidi both the historic and collective nature of trauma. Tekin et al. (2016) estimate that the prevalence of PTSD amongst Yezidi survivors seeking refuge in neighbouring Turkey is close to $43 \%$.

In January 2015, on the invitation of the Free Yezidi Foundation-an International NGO Agency, a scoping mission was carried out to determine the psychological needs of Yezidi survivors who had managed to escape their ISIL Jihadist captures. Six in-depth interviews were carried out with female Yezidi survivors who had been 
rescued from ISIL. Table 1 highlights the pattern of their trauma experiences and an outline of their trauma symptoms (Farrell 2016b).

The six Yezidi survivors shared phenomena that fell into two interesting categories: trauma experiences that they were willing to disclose and those they would not disclose. The latter are implicit traumas that were 'not to be spoken of or shared'; they could be alluded to, suggested, but not directly expressed, thus remaining 'unspoken'. Trauma survivors whose experiences involve shame, profound guilt, fear, retribution or disgust are often unable to then relate their experiences-as if language seems to lose its purpose, in conveying their depth of suffering and the true extent of the magnitude of their loss. Accordingly, the trauma often feels unspeakable as language itself seems insufficient in truly conveying the experience in all its detail (van der Kolk 2015). A further rationale for non-disclosure may also centre upon selfprotection/self-preservation factors.

Eye Movement Desensitisation and Reprocessing (EMDR) Therapy is a standardised, eight-phase, traumafocused therapy, involving the use of bilateral eye movements, tactile or acoustic stimulation. Targeted traumatic memories are considered in terms of its core elements-the most distressing visual aspect of the memory (image), the associated cognition related to that image, along with its concomitant affect and body sensation. These four components are then focused on as dual attention stimulation occurs. It is hypothesised that
EMDR Therapy stimulates the individual's own information processing in order to help integrate the targeted memory as an adaptive contextualised memory. Processing targets involve past events, present triggers and adaptive future functioning. EMDR Therapy at times uses restricted questioning related to cognitive processes paired with working memory taxation to unblock processing (Shapiro 2018, p. 21; De Jongh et al. 2013). The basis of EMDR Therapy is the Standard Protocol (SP).

Most of the current empirically supported therapies (EST) for treating PTSD involve exposure-based interventions that require the 'telling of the story'. This repeated retelling of the story brings about a reduction in levels of distress, but also allows the trauma to be subjected to cognitive challenge and restructure, by challenging viewpoints, perspectives, evidence-base, probability, cost-benefit analysis, etc. What many of the ESTs for treating trauma have in common requires an open disclosure of the trauma narrative. This raises an interesting question-what if the trauma survivor is unwilling to share their trauma experience, how then can we directly address this trauma material?

A potential solution exists within EMDR Therapy using a 'blind' version of the Standard Protocol. This 'Blind 2 Therapist (B2T) (Farrell and Reid 2019) version can be used when implicit trauma experiences involve deeprooted shame, excessive guilt, fear, disgust or retribution anxiety. Table 2 highlights the primary differences between the Standard Protocol and the Blind 2 Therapist version within EMDR Therapy.

Table 1 Pattern of trauma experiences and symptoms encountered by six female Yezidi survivors rescued from ISIL

\begin{tabular}{|c|c|}
\hline Thematic narratives experienced by Yezidi survivors: & Trauma symptom experiences of Yezidi survivors \\
\hline $\begin{array}{l}\text { o ISIL attack the Yezidi community in Northern Iraq } \\
\text { o This involves high levels of terror, fear and extreme violence-including } \\
\text { deliberate acts of humiliation and dehumanisation } \\
\text { o Members of the Yezidi community are segregated with families separated } \\
\text { and torn apart } \\
\text { o Yezidi males are brought in front their community and then massacred } \\
\text { o Yezidi females (particularly young woman) are abducted—being moved, in } \\
\text { some cases, great distances } \\
\text { o The Yezidi survivors interviewed spent periods in large groups with other } \\
\text { women following their immediate abduction—-this increased individual and } \\
\text { collective levels of terror and fear } \\
\text { o These abducted women and young girls are then sold as 'sex slaves' to } \\
\text { ISIL fighters } \\
\text { o Many survivors were sold for small amounts of money (approximately } \\
\text { \$15-30-in some cases, for as little as a packet of cigarettes) } \\
\text { o Virgin Yezidi girls were highly prized by ISIL fighters/jihadists } \\
\text { o Once in captivity, survivors are subjected to repeated sexual, physical } \\
\text { and psychological violence; torture; } \\
\text { and humiliation } \\
\text { o Several Yezidi survivors described making attempts at suicide and self-harm } \\
\text { o A frequent trauma narrative by Yezidi survivors—a choice: 'convert to Islam } \\
\text { and have one } \\
\text { husband' or 'keep your Yezidi faith' and you will be passed from one Jihadist } \\
\text { to another (multiple abusers } \\
\text { o Those that managed to escape-their families had to pay large ransoms } \\
\text { (approximately \$5000), with very little means to repay this } \\
\text { o Yezidi survivors recounted that the Yezidi community has been very } \\
\text { welcoming to those fortunate to return }\end{array}$ & $\begin{array}{l}\text { o Flashbacks and intrusive recollections } \\
\text { o Nightmares and poor sleep pattern } \\
\text { o Heightened anxiety } \\
\text { o Helplessness } \\
\text { o Feelings of self-blame and 'over-responsibility' } \\
\text { o Powerlessness } \\
\text { o Feeling detached } \\
\text { o Suicidal thoughts and self-destructiveness } \\
\text { o Low mood/depression } \\
\text { o Phobic reactions } \\
\text { o Low self-esteem } \\
\text { o Difficulty managing emotions } \\
\text { o Changes in 'world view' } \\
\text { o Changes in consciousness } \\
\text { o Anger and resentment } \\
\text { o Over-responsibility } \\
\text { o High levels of shame/guilt } \\
\text { o Heightened sense of fear and anxiety } \\
\text { o Fear of retribution: rationale and irrational } \\
\text { o Disgust } \\
\text { o Secrecy } \\
\text { o Transference/counter-transference } \\
\text { o Quasi power and control } \\
\text { o When there are 'no words' and language is 'insufficient' } \\
\text { o Unspoken trauma }\end{array}$ \\
\hline
\end{tabular}


Table 2 Core components of the EMDR Therapy phases and protocols: Standard versus B2T

\begin{tabular}{lll}
\hline EMDR Therapy: 8 phases & EMDR therapy Standard Protocol [SP] phase 3 & EMDR Therapy Blind 2 Therapist [B2T] protocol phase 3 \\
\hline O Phase 1: history taking & o Target memory & o Target memory - cue word \\
O Phase 2: preparation & o Worst part & O Emotions \\
O Phase 3: assessment & o Negative cognition (NC) & o Subjective unit of disturbance (SUD) \\
O Phase 4: desensitisation & O Positive cognition (PC) & o Location of body sensation \\
O Phase 5: installation & o Validity of cognition (VOC) & \\
O Phase 6: body scan & o Emotions & \\
O Phase 7: closure & o Subjective unit of Disturbance (SUD) & \\
o Phase 8: re-evaluation & o Location of body sensation &
\end{tabular}

Although both SP and B2T serve the same goal in accessing and activating the respective trauma memory ready for trauma confrontation and subsequent processing, in B2T, the client reveals no details about the memory to the therapist, nor offers any insights into traumarelated cognitions or belief systems. Negative posttrauma cognitions play a central role in several conceptual models of the aetiology and maintenance of PTSD (Brown et al. 2019). For example, in EMDR Therapy, cognitions are a verbalization of emotional and somatic experiences. The rationale for 'non-disclosure' of cognitions in $\mathrm{B} 2 \mathrm{~T}$ is that disclosure has the potential to be 'too revealing' - for a variety of reasons. If a client does not wish to 'share their trauma narrative' explicitly-this presents a significant clinical challenge when using exposure-based treatment interventions. In certain circumstances revealing cognitions/beliefs/schemas themselves may become an obstacle in accessing/activating the trauma memory in the EMDR Therapy Assessment Phase. However, if cognitions are overtly expressed by the client during $\mathrm{B} 2 \mathrm{~T}$, therapists are encouraged to utilise them.

The premise for the 'Blind 2 Therapist Protocol' was first alluded to by Shapiro (2001) influenced by Bessel van der Kolk's experience of undertaking EMDR Therapy training in the early 1990s. Blore et al. (2013), influenced by his earlier work (Blore 1997) of using B2T with coal miners and mines rescue workers, developed the first worksheet in using this protocol and demonstrated its effectiveness within six vignettes. However, practicebased evidence from various trauma capacity building projects found that the existing B2T Protocol (Blore and Holmshaw 2009) needed clarification about certain aspects as problems were experienced in understanding the protocol and were subsequently being lost in translation. Consequently, a modified B2T Scripted Protocol version was developed with sensitivity to cultural appropriateness and adaptability (Farrell 2018; Naseh et al. 2019). This modified version has since been applied within Trauma Capacity Building Projects in Myanmar, Palestinian Territories, Cambodia and Iraq.

The purpose of the present study was to test this Blind 2 Therapist protocol within two projects. More specifically, project 1 evaluated the EMDR Therapy Blind 2
Therapist (B2T) protocol and compared it with the EMDR Therapy Standard Protocol (SP). A quasiexperimental methodology single-subject design was chosen to test four hypotheses. A single-subject design is often used in applied psychology research in which the subject serves as her/his own control, rather than using another individual or group (Lobo et al. 2017). This study used pre- and post-testing of both the control (SP) intervention versus the experimental (B2T) intervention. The nature of the $\mathrm{B} 2 \mathrm{~T}$ intervention meant that randomisation was not possible, as it would have been unethical to randomise beneficiaries out of the treatment programme once they have been informed that they have been referred in and are expecting the treatment. The hypotheses tested were that the EMDR Therapy Standard Protocol (1) would be safer (no adverse effects), (2) more effective, (3) more efficient and (4) more relevant to a trauma population than B2T. Project 2 investigated the EMDR Therapy Blind 2 Therapist Protocol for clinical applicability with Yezidi survivors $(N=8)$.

\section{Methodology}

\section{Setting}

Both studies were undertaken as part of a Trauma Capacity Building Project for Northern Iraq in the Kurdistan Region in the Middle East. It was coordinated by Trauma Aid Germany-a non-governmental organisation (NGO) - and the School of Psychology, University of Worcester (UK), in partnership with a local NGO Jiyan Foundation for Human Rights and Torture. The research took place in Erbil, the capital city of the Kurdistan Regional Government.

\section{Sample}

The study used a self-select convenience sample of beneficiaries who had encountered human rights abuses perpetrated in Iraq during the last 40 years. The scope of human rights violations included survivors of torture, long-term detention, chemical attacks, genocidal campaigns, forced displacement, war and military conflict, terrorist activity, assassinations, kidnappings, ethnic cleansing, religious persecution, rape and sexual violence, oppression and gender-based violence. The research participants for research project 1 were therapists 
from the Jiyan Foundation for Human Rights and Torture, all of which had been born in the last 40 years, and therefore had first-hand experience of human rights abuses in Northern Iraq. This research population consisted of $N=$ 65 therapists from within the Jiyan Foundation. As will be highlighted later, the study used a within-subject design as the research participants were subjected to both treatment intervention protocols-Standard Protocol $(N=89)$ and Blind 2 Therapist $(N=91)$. One of the many primary beneficiaries within the Jiyan Foundation for Human Rights were Yezidi survivors-and therefore for project $2-N=8$ Yezidi Survivors of ISIL were recruited.

\section{Study structure}

Ethical approval for the study was granted by the University of Worcester. In addition, permission was granted from the Jiyan Foundation for Human Rights and Torture with regard to access to study participants.

\section{Study 1}

Research project 1 was based upon a replication of Shapiro (1989) Efficacy of Eye Movement Desensitization Procedure in the Treatment of Trauma Memories-this seminal publication outlined the origins of $\operatorname{EMD}(\mathrm{R})$ Therapy. Lobo et al. (2017) consider that single-subject designs are where the subject serves as their own control rather than using another individual or group. Therefore, research participants undertook self-selection by deciding for themselves whether they would experience either SP or B2T: when targeting a trauma memory of their choosing. Once the beneficiary had made their decision, the treating therapist fully respected this and adhered to the SP of B2T accordingly. Each session was closely monitored and subjected to 'live' EMDR Therapy clinical supervision (EMDR Europe Accredited Consultant) meaning that the consultant observed the entire process. After the treatment intervention, a 'post-session' debrief was also carried out by the same consultant. The debrief served many purposes within the research study including quality assurance, protocol and treatment fidelity-check feedback, and post-session debrief (client and therapist) and therefore was an essential means of data collection. In the B2T protocol, the pre-validity of cognition (VOC) measure is not taken during the phase 3 assessment. Nonetheless, in this study, the pre-VOC was ascertained retrospectively during the debrief session-purely as an indicator of any potential change as perceived by the beneficiary. The debrief was also used as an opportunity to obtain qualitative data.

\section{Data collection for study 1}

Data for project 1 was collected during the EMDR Therapy levels 2 and 3 training events which were held in Erbil, Northern Iraq. Each clinical session was carried out in the client's indigenous language. In addition, experienced translators were used, who were familiar with psychology, treatment and EMDR Therapy, who offered direct translation of each session between therapist and client. Every treatment session used a triadic model: therapist, client and observer. The role of the observer was to assist and support the therapist, and in addition to time (in minutes), the intervention from commencement of EMDR Therapy phases 4 to the end of EMDR Therapy phase 6. Furthermore, each session was also supervised 'live' by an EMDR Europe Accredited Consultant/Clinical Supervisor, using an EMDR Therapy Research Fidelity Checklist ${ }^{1}$ to ensure adherence to either the Standard Protocol or B2T Protocol.

During the delivery of both the SP and B2T interventions, time taken (in minutes) was measured for phases 4 (desensitisation), 5 (installation) and 6 (body scan) with specific regard to the material pertaining to the chosen target memory. As mentioned earlier, further qualitative data was obtained from the debrief sessions.

Data was collected pre- and post-intervention and at 6-month and 12-month follow-up. The 6- and 12-month follow-up occurred during level 3 and clinical supervision/case consultation events. At these events, each research participant experienced phase 8: re-evaluation, which allowed the participant to 'reconnect' with their original target memory and disclose their respective, presently held subjective measures.

\section{Measures}

For the purpose of research project 1 (and 2), two subjective units of measurement were utilised-subjective unit of disturbance (SUD) and the validity of cognition (VOC). These were the two primary units of measurement used in the original Shapiro (1989) study.

The SUD scale, first developed by Wolpe and Lazarus (1966), utilises an 11-point scale where $0=$ no disturbance and $10=$ highest level of disturbance. The purpose of the SUD is to subjectively measure the level of disturbance of the trauma memory targeted for processing. A second subjective measure is the VOC, which according to Shapiro (1989) provides a rapid assessment of cognitive structure on an emotional/somatic level rather than intellectual. Both SUD and VOC have been extensively used with documented validity, reliability, and correlations with several physiological indices of distress (Shapiro 1995, 2001, 2018).

Hypotheses 1 and 2 were tested using the SUD and VOC scales for the trauma memories being targeted in both the control (SP) and the experimental (B2T)

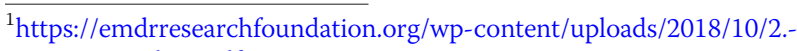
EFRS-Manual-v2.pdf 
groups. A reduction in the SUD and an increase in the VOC would indicate a safely applied, treatment effect.

To test hypothesis 3 , time (in minutes) was used to measure the duration (in minutes) of each intervention [SP and B2T] from the start of phase 4 (desensitisation) to the end of phase 6 (body scan).

Hypotheses 4 was tested by asking research participants the following question: 'Would you be willing to give one word (or more) to describe the nature of the trauma event that you worked on using the B2T treatment intervention?' Those participants who agreed to answer the question were instructed to write 'one word' (or more) using their own indigenous language. This was an anonymous and confidential process. The answers were then translated by one of the official translators involved in the project. This dataset was then used to establish an index of potential therapeutic effectiveness using both SUD and VOC as units of measurement pre-, post-, 6-month and 12-month follow-up. A content analysis of the target memories was used for B2T treatment group. As mentioned earlier, qualitative transcript data was collected from the therapists debriefing sessions post-interventions for both SP (control) and B2T (experimental) groups. These 'post-session' debriefs were carried out by EMDR Europe Accredited Consultants. As part of the debrief, the 'client' was asked two further questions specifically in relation to when they experienced the B2T protocol: (1) 'Would you have worked on this memory with the SP - Yes or No?' (2) 'Would you be willing to disclose your trauma memory after using B2T - Yes or No?' All of this data were essential in determining the relevance of B2T in this environment, with these beneficiaries, in accordance with testing hypothesis 4 .

\section{Data analysis}

For testing hypotheses 1, 2 and 3, a Mann-Whitney $U$ test was used to compare the SP (control) with B2T (experimental) protocols in relation to SUD and VOC. The Mann-Whitney $U$ test is a non-parametric alternative test to the independent sample $t$ test and is used to compare two sample means of the same population to determine equivalence or not and used to test whether two sample means are equal or not (McKnight and Najab 2010). Of note, this test is useful when ordinal and continuous variables are not normally distributed. Results from the MannWhitney yields $Z$ scores (how many standard deviations an element is from the mean) and $p$ values (level of marginal significance as part of statistical hypothesis testing).

\section{Results study 1}

Data results from the Jiyan Foundation therapists as research participants

In testing hypothesis 1 , Fig. 2 and Tables 3 and 4 highlight the SUD and VOC scores pre-, post-, 6-month and 12-month follow-up; mean, mode and STD; and Zscores and $p$ values between the control group (SP) and the experimental group (B2T).

In regard to the SUD, the treatment effect was demonstrated in two ways-reduction in the SUD during the session and the then subsequent maintenance of this treatment effect at 6- and 12-month follow-up. These observations indicate that the trauma memory was processed effectively during the treatment session and remained processed at 6- and 12-month follow-up. Between SP and B2T, there was no difference in pre-measures $(Z=1.89, p=0.59), 6$

\section{CONTROL GROUP - STANDARD PROTOCOL [ $\mathrm{N}=89$ ] VERSUS EXPERIMENTAL GROUP - B2T [ $N=91$ ]}

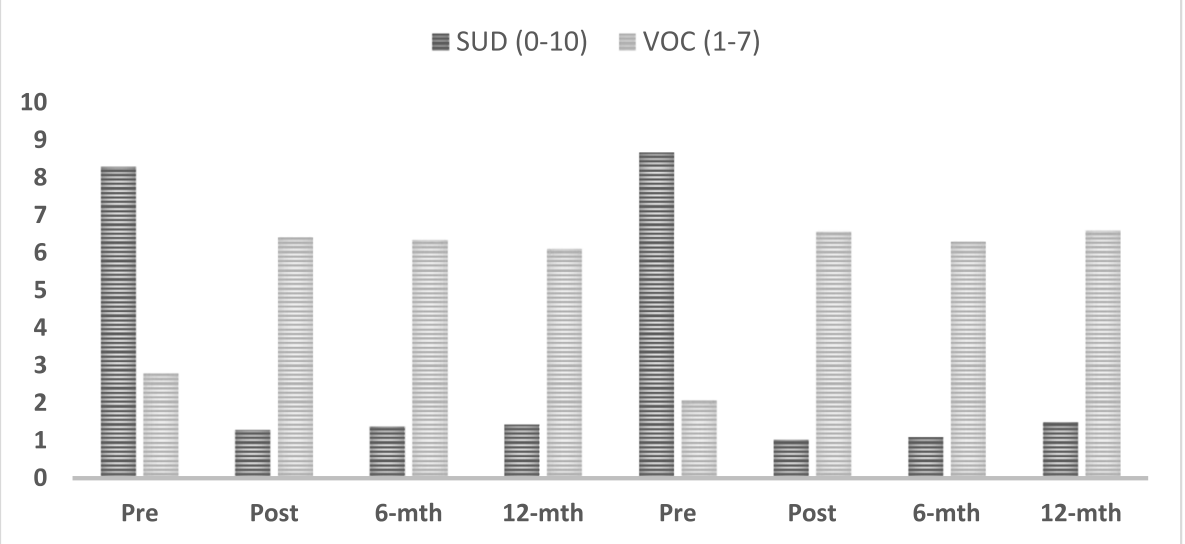

EMDR Therapy Standard Protocol

EMDR Therapy B2T Protocol

Fig. 2 EMDR Therapy Standard Protocol $(N=89)$ versus Blind 2 Therapist Protocol $(N=91)$ SUD and VOC scores pre-, post- and 6 months follow-up 
Table 3 Standard Protocol $(N=89)$ versus Blind 2 Therapist $(N=91)$ SUD and VOC, pre-, post- and 6 months follow-up. Mean, SD and mode values

\begin{tabular}{|c|c|c|c|c|c|c|c|c|c|c|c|c|c|c|c|c|}
\hline \multicolumn{9}{|c|}{ Standard Protocol (control group) $N=89$} & \multicolumn{8}{|c|}{ Blind-2-Therapist Protocol (experimental group) $N=91$} \\
\hline Time & $\begin{array}{l}\text { Pre- } \\
\text { SUD }\end{array}$ & $\begin{array}{l}\text { Post- } \\
\text { SUD }\end{array}$ & $\begin{array}{l}\text { 6-month } \\
\text { SUD }\end{array}$ & $\begin{array}{l}\text { 12-month } \\
\text { SUD }\end{array}$ & $\begin{array}{l}\text { Pre- } \\
\text { VOC }\end{array}$ & $\begin{array}{l}\text { Post- } \\
\text { VOC }\end{array}$ & $\begin{array}{l}\text { 6-month } \\
\text { VOC }\end{array}$ & $\begin{array}{l}\text { 12-month } \\
\text { VOC }\end{array}$ & $\begin{array}{l}\text { Pre- } \\
\text { SUD }\end{array}$ & $\begin{array}{l}\text { Post- } \\
\text { SUD }\end{array}$ & 6-month & $\begin{array}{l}\text { 12-month } \\
\text { SUD }\end{array}$ & $\begin{array}{l}\text { Pre- } \\
\text { VOC }\end{array}$ & $\begin{array}{l}\text { Post- } \\
\text { VOC }\end{array}$ & $\begin{array}{l}\text { 6-month } \\
\text { VOC }\end{array}$ & $\begin{array}{l}\text { 12-month } \\
\text { VOC }\end{array}$ \\
\hline$\overline{M e a n}$ & 8.29 & 1.29 & 1.56 & 1.44 & 2.81 & 6.41 & 6.44 & 6.11 & 8.67 & 1.03 & 1.5 & 0.94 & 2.07 & 6.56 & 6.29 & 6.59 \\
\hline STD & 1.3 & 0.72 & 1.61 & 1.24 & 1.05 & 0.62 & 0.63 & 1.05 & 1.05 & 0.8 & 1.41 & 0.83 & 1.13 & 0.54 & 0.55 & 0.51 \\
\hline Mode & 8 & 1 & 1 & 1 & 3 & 6 & 6 & 7 & 9 & 1 & 1 & 1 & 1 & 6 & 6 & 7 \\
\hline
\end{tabular}

months $(Z=-2.35, p=0.03)$ and 12 months $(Z=0.18, p$ $=0.86)$; however, results were significant at post-session $\left(Z=-2.35, p=0.019^{*}\right)$, though as results suggest, this was not maintained at either the 6- or 12-month followup points. The pre-VOC scores between SP and B2T were significant $\left(Z=-4.47, p=0.0001^{* * *}\right)$ but not at postsession $(Z=1.54, p=0.12), 6$ months $(Z=1.19, p=0.23)$ and 12 months $(Z=0.84, p=0.35)$. During the posttreatment debrief sessions, research participants confirmed that both SP and B2T were 'well-tolerated' and proved their utility in accessing and activating the disturbing memory, which was being targeted for trauma processing. Both the SUD and VOC scores at post-, 6-month and 12-month follow-up suggest that both treatment interventions were well-tolerated and effective. Furthermore, the EMDR consultants who were observing the process confirmed high treatment fidelity in respect of the application of the SP and B2T protocols concluding that they had been appropriately, consistently and effectively applied. Therefore, a combination of the empirical data-reduction and maintenance of the reduction in SUD scores at pre-, 6- and 12-month follow-up, feedback from the research participants about their subjective experiences and feedback from the EMDR consultants regarding the application of either SP or B2T-suggests that both SP and B2T were 'safe' and effective' as a treatment intervention for a disturbing trauma memory, and therefore, hypotheses 1 and 2 were rejected.

Hypothesis 3 tested efficiency between SP and B2T comparing differences in time for phase 4 desensitisation, phase 5 installation and phase 6 body scan between SP [ $N$ = 89] $($ mean $=37.4 \mathrm{~min}$, mode $=30 \mathrm{~min}$, STD $8.69 \mathrm{~min})$ and B2T $[N=91]$ (mean $=33.45 \mathrm{~min}$, mode $=30 \mathrm{~min}$, STD $=8.5$ ). Although results highlight a difference in mean time between SP and B2T $(Z=-2.14, p=0.32)$, which suggested that the B2T protocol may be potentially more 'efficient' than SP, however, this difference was not statistically significant. Therefore, we conclude that in this study, there is no difference in efficiency between SP and $\mathrm{B} 2 \mathrm{~T}$, and therefore, hypothesis 3 is duly rejected.

Hypothesis 4 was tested via content analysis. This was based upon material obtained from each of the postsession debriefs. In total, 180 EMDR Therapy clinical sessions were completed within the context of the research for both the control group ( $\mathrm{SP}=89$ ) and the experimental group $(\mathrm{B} 2 \mathrm{~T}=91)$. A meta-analysis of the debrief sessions with the EMDR Europe Consultants ascertained that during the treatment sessions, fidelity to both SP and B2T was extremely high and that sessions had been carried out in a robust, ethical, sensitive and competent manner.

As noted earlier, qualitative data was obtained relating to the two debrief questions ( 1 and 2$)$. In regard to question 1 , results indicated that $90 \%$ of the research participants would not have worked on their chosen trauma memory if they had not been for using the B2T protocol. If only SP had been available, which requires disclosure of the memory, they would not have chosen to work on this memory at all. Relating to question 2, 85\% of the research participants actually disclosed already their trauma experiences during the $\mathrm{B} 2 \mathrm{~T}$ treatment session. This raises a further question as to whether there is any correlation between level of SUD (mean $=8.67$, STD $=$ 1.05 , mode $=9$ ) and eventual disclosure of the nature of the trauma experience. These results also assist in further reflections upon hypotheses 1 and 2 in indicating that the 'high' rate of willingness to disclose trauma experiences further demonstrates 'safety' and 'efficacy'.

Further results from the analysis of the debrief sessions considered a content analysis of the disclosed trauma

Table 4 Mann-Whitney $U$ test SUD and VOC pre-, post- and 6 months follow-up

\begin{tabular}{lllllllll}
\hline & $\begin{array}{l}\text { SUD pre } \\
\text { (SP/B2T) }\end{array}$ & $\begin{array}{l}\text { SUD post } \\
\text { (SP/B2T) }\end{array}$ & $\begin{array}{l}\text { SUD 6 months } \\
\text { follow-up (SP/B2T) }\end{array}$ & $\begin{array}{l}\text { SUD } 12 \text { months } \\
\text { follow-up (SP/B2T) }\end{array}$ & $\begin{array}{l}\text { VOC pre } \\
\text { (SP/B2T) }\end{array}$ & $\begin{array}{l}\text { VOC post } \\
\text { (SP/B2T) }\end{array}$ & $\begin{array}{l}\text { VOC 6 months } \\
\text { follow-up (SP/B2T) }\end{array}$ & $\begin{array}{l}\text { VOC 12 months } \\
\text { follow-up (SP/B2T) }\end{array}$ \\
\hline$Z$-score & 1.89 & -2.35 & 0.027 & 0.176 & -4.473 & 1.537 & 1.186 & 0.845 \\
$p$ value & 0.586 & $0.019^{*}$ & 0.976 & 0.861 & $0.0001^{* *}$ & 0.124 & 0.234 & 0.347 \\
\hline
\end{tabular}

$S P$ standard EMDR Therapy protocol, B2T Blind 2 Therapist EMDR Therapy Protocol

*Significant at $p<.05$

** Significant at $p<.01$ 
experiences from the B2T protocol (experimental group), although there was some clustering around certain trauma experiences, many of which were consistent with criterion A of the PTSD diagnostic frameworks as per DSM-5 (APA 2013) and ICD 11 (WHO 2019). Table 5 highlights the major themes:

Table 5 outlines the traumatic target memories, targeted in therapy, which the research participants were willing to disclose post-B2T treatment intervention. As the table highlights, many of these traumas are consistent with criterion A PTSD. The results of this study highlight are the treatment effect in using $\mathrm{B} 2 \mathrm{~T}$, but also that the intervention appeared to be safe, was well tolerated, effective as an intervention and relevant to the trauma experiences targeted for processing. Therefore, hypothesis 4 was rejected.

\section{Discussion project 1}

The rationale for this study was to test a specific EMDR Therapy Protocol - Blind 2 Therapist (B2T) in comparison with the Shapiro Standard Protocol (SP) with regard to safety, effectiveness, efficiency and relevance. Overall, the results from project 1 are promising; however, they should be viewed with some degree of caution. As in the original Shapiro (1989) study, no attempt was made to determine any clinical/ diagnostic indication of the research participant group for project 1-the rationale for this was to purely test the applicability of the B2T protocol. Figure 2 highlights the impact of a one-session intervention with both SP and B2T in regard to SUD and VOC and that these results were consistent at 6- and 12-month follow-up. As interesting as the results may be, caution is indicated in questioning why the SUD scores were not lower, and the VOC not higher in comparison with Shapiro's (1989) original study. It is important to highlight that in Shapiro's study, Eye Movement

Table 5 Major themes of target trauma memories used for B2T protocol $(N=91)$
o Rape
o Witnessing a murder
o Traumatic bereavement
o Serious road traffic collision
o Bullying in the workplace
o Bullying by mother-in-law
o War related conflicts and incidents
o Gender-based violence
o Chemical attack ordered by Saddam Hussain
o Torture
o Attacked by dog
o Imprisonment
o Vicarious trauma—mainly around atrocities

Desensitisation (EMD) was used rather than the Standard Protocol. When considered from a clinical perspective, such results indicate that the research participants would most likely have benefited from further treatment. However, the specific intention of the study was to replicate the original Shapiro (1989) methodology in testing the protocol rather than examine a comprehensive treatment plan for a set diagnosis.

As Table 4 demonstrates, there was no difference in the mean, STD and mode scores between the two groups (SP and $\mathrm{B} 2 \mathrm{~T}$ ). Although there was a degree of significance between the SUD post (SP/B2) and VOC pre (SP/B2), these were not carried through at both 6 months and 12 months. Table 5 demonstrates that there is no statistically significant difference between SP and $\mathrm{B} 2 \mathrm{~T}$ in regard to this specific research population; however, further research is needed to explore this in more detail with distinct clinical populations.

The difference in time (mean) between SP and B2T is interesting, but again proved statistically insignificant. However, as Table 6 testifies, the major themes of the target trauma memories used by the $(N=91)$ research participants using B2T would satisfy criterion A of a PTSD diagnosis. Furthermore, the post-debrief session highlighted two significant aspects; firstly, research participants would have chosen to have not worked on a particular memory if only the EMDR Therapy SP was available; secondly, there is a suggested correlation between level of SUD and non-disclosure. As the level of SUD diminishes, the research participant is more likely (85\%) to disclose the trauma memory. A reasonable conclusion therefore is that having the $\mathrm{B} 2 \mathrm{~T}$ protocol available promotes great choice for clients, but also allows them to be more in control of their own process.

For the research, the debrief sessions were an essential means to consolidate learning, provide qualitative feedback and allow for data collection, but more importantly, they acted as a quality assurance measure to ensure that the client (receiving either SP or B2T) was grounded

\begin{tabular}{|c|c|c|c|c|c|}
\hline Client & Type of trauma & Pre SUD & Post SUD & Post VOC & Disclosure \\
\hline 1 & Shame-based & 9 & 3 & 6 & Yes \\
\hline 2 & Shame-based & 9 & 2 & 6 & No \\
\hline 3 & Fear of retribution & 10 & 1 & 6 & Yes \\
\hline 4 & Shame-based & 10 & 2 & 6 & No \\
\hline 5 & Both & 10 & 2 & 6 & Yes \\
\hline 6 & Shame-based & 10 & 1 & 6 & Yes \\
\hline 7 & Both & 8 & 2 & 6 & No \\
\hline \multirow[t]{2}{*}{8} & Shame-based & 10 & 1 & 6 & Yes \\
\hline & Mean & 9.5 & 1.75 & 6 & \\
\hline
\end{tabular}


and actively present in the 'here and now' after the treatment intervention. As the research only involved one treatment session, 'duty of care' measures were employed that facilitated access to additional support networks and liaison with colleagues who would be involved in further intervention, if required.

\section{Project 2: Jiyan therapists using B2T with $N=8$ Yezidi survivors}

The intention of this project was to carry out an action research initiative to test the B2T directly on Yezidi survivors using therapists from the Jiyan Foundation for Human Rights and Torture. The rationale for action research on current beneficiaries was to improve the utilisation of B2T with Yezidi survivors based upon knowledge and information obtained from project 1 . According to Stringer (2013), the action research process involves three basic phases: look, think and act. The primary objective of action research is to develop a collective self-reflective enquiry to improve both the rationality and justice of educational practices (Kemmis and McTaggart 1988).

The research protocol for project 2 involved identifying, within the Jiyan Foundation Treatment Centers, specific beneficiaries-Yezidi survivors of ISIL Jihadists-who were reluctant to disclose their trauma experiences. Treatment was carried out by one of the therapists who were trained by the Jiyan Foundation.

The client was informed about the EMDR Therapy B2T Protocol and invited to voluntary participate in a research project examining $\mathrm{B} 2 \mathrm{~T}$ and its clinical effectiveness in practice. The client was asked to identify the 'worst memory' and use it as a target within B2T. It was emphasised to the client that they were under no obligation to disclose any material whatsoever during, or after the treatment session, and that they were the ones in control of any choice to disclose. Each of the clinical sessions was supervised by an EMDR Europe Accredited Consultant. As with project 1 , no attempt was made to gather clinical diagnosis or any psychometric data. The rationale for this was to purely test the $\mathrm{B} 2 \mathrm{~T}$ protocol with regard to the four research hypotheses. The only modest difference was that no attempt was made to obtain the VOC retrospectively-just pre- and post-SUD and post-VOC.

\section{Project 2 results \\ Project 2: Jiyan therapists using B2T with $N=8$ Yezidi survivors}

For this part of the research, the participants needed to be specific beneficiaries from any of the Jiyan Foundation Clinical Centres, who were: i. Yezidi survivors of ISIL captured and sold as 'sex slaves'

ii. Either escaped or rescued from their captures

iii. Returned to their surviving families

Eight participants were included in the study. Each research participant was asked to identify a 'worst' trauma memory and to then have this targeted with the B2T protocol only. It was emphasised consistently throughout the contact with the research participants that there was no expectation being placed upon them to disclose the content of any material. The clinical session was clinically supervised by an EMDR Europe accredited consultant. Research participants were asked to divulge whether it was a trauma that was either 'shame-based', fear-based or both. Permission to utilise this data set was granted by the Jiyan Foundation for Human Rights and Torture. Results are highlighted in Table 6 and Fig. 3

Results indicate that the EMDR Therapy B2T Protocol was safe, well-tolerated, effective, efficient and relevant for working with the implicit trauma experience of the Yezidi survivors.

\section{Discussion project 2}

As highlighted earlier, one of the primary beneficiaries of the Jiyan Foundation for Human Rights is the Yezidi population. As Table 6 and Fig. 3 consider-the eight research participants, used in this part of the study, were unwilling to disclose a particular trauma memory. The mean SUD (pre) utilisation of B2T is 9.5. It would be reasonable to assume that there may be two reasons for this unwillingness to disclose: firstly, factors within the recipient, the high levels of shame and their fear of retribution, and secondly, factor relating to the interpersonal dynamic, associated with therapist characteristics. Notably, a significant component of the trauma experience of the Yezidi is the religious identity of their persecutors as Muslim; the Yezidi have been subjected to religious persecution over many centuries, with the goal of converting Yezidis to Islam. However, this interpersonal factor was not examined specifically; it may be a potential area of further study. Results from our study suggest a significant treatment effect using B2T on implicit trauma memories whether these were 'shame'-based or 'fear of retribution'-based trauma episodes. However, returning to a previous question-is there a correlation between the level of SUD and non-disclosure?-although this was not specifically tested in our study, results seem to indicate that a potential correlation exists.

\section{General discussion}

The results of this study provide support for the safety, effectiveness, efficiency and relevance of B2T protocol application intervention within EMDR therapy. The 
Yezidi Survivors of ISIL using B2T Protocol ( $\mathrm{N}=8$ ) Mean SUD Pre and Post Treatment Session

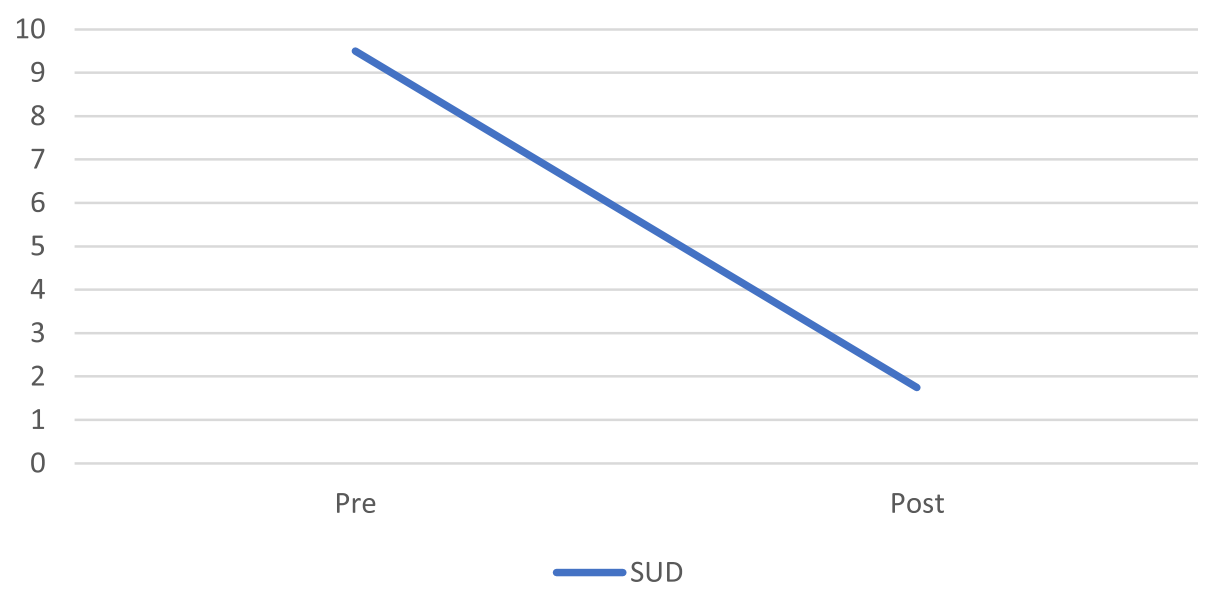

Fig. 3 Mean pre- and post-measures of SUD with Yezidi survivors using B2T EMDR Therapy Protocol

results suggest that this protocol has several distinct advantages in terms of clinical application, over other more 'exposure-based' treatment interventions, which require trauma narrative disclosure; these advantages appear all the more beneficial when they are considered in the "theatre' context. The current results support the effectiveness of B2T with highly vulnerable trauma populations, such as Yezidi survivors. There is a need to undertake further exploration of the potential benefits from using B2T as part of psychological trauma treatment options and to focus on broader aspects such as clinical diagnoses and complete treatment intervention programmes.

It would be important to emphasize that B2T is certainly a blunter instrument than the Standard Protocol as cognitions, beliefs and schemas are inherent parts of trauma memories, and therefore, their elucidation within SP offers greater clarity, precision and finer tuning of the trauma memory being activated. However, that said, B2T provides an important clinical option, and more significantly for the client, it empowers them: enhancing decision-making, allowing the client the choice of working on a trauma memory network without the need for disclosure. Working clinically with 'blind targets' using the B2T Protocol is challenging. The B2T protocol still satisfies the core elements of EMDR Therapy: activation of a trauma memory, stimulation of the memory bilaterally and through dual attention the facilitation of a desensitising, reprocessing of the memory, so that it becomes a memory remembered, rather than re-experienced. Thus, within B2T, the core elements of EMDR Therapy are still present and adhered to.

The rationale for not using cognitions in B2T centres upon several reasons. Cognitions themselves may in turn be perceived as 'too revealing', and their articulation could possibly become an obstacle in activating the trauma memory in EMDR Therapy phase 3 assessment. However, if cognitions are overt when using B2T, therapists are encouraged to utilise them. What the research findings suggest is a potential correlation between levels of shame (for example) and levels of disturbance (SUD); however, this requires further investigation and consideration. Notably, as the level of SUD reduces, there is an increased probability the client will eventually disclose the nature of their trauma experience. Thirdly, their non-inclusion appears to have an empowerment effect on the client, further reinforcing that they are in control of their own reprocessing of their trauma experience.

The design of this particular study should also be subjected to critical consideration. One of the disadvantages of the study is that being previously exposed to treatment (1) and then treatment (2) potentially leads to a 'carryover effect' as the knowledge and experience acquired from treatment 1 can be potentially transferred into treatment 2. A further drawback is that results could be influenced by 'practice effects'. This research (project 1) took place in a teaching and learning environment where the clinical practice elements were receiving 'live clinical supervision' by an EMDR Therapy consultant. Participants received regular feedback and guidance from the EMDR consultants who are facilitating the educational environment. Understandably, the research participants will be integrating this feedback so as to improve and develop their skills further. This is why there will be potential transfer from treatment 1 to treatment 2 , as the research participants become more skilled, confident and competent.

Another critical consideration is that the study did not consider any pre-existing factors. For example, in 
research project 1 , research participants were not identified as a distinct clinical population; although the disclosed trauma memories were of major incidents, future research, considering replication, should consider using more direct clinical populations, preferably either PTSD or complex PTSD. Other explorations should also consider the impact of B2T of factors such as posttraumatic growth and resilience. Another limitation is that the study did not consider influences outside of the experiment itself, such as the political situation in Northern Iraq and the operation to liberate Mosel for example-this would be worthy of further research and investigation. Conversely, an advantage of this study was the within-subject design of this experiment as the same group of participants were subjected to both treatment intervention protocols-EMDR Therapy Standard Protocol [treatment 1] versus Blind-2-Therapist (B2T) [treatment 2]. This type of design has two distinct advantagesit makes it easier to detect differences across levels of independent variables because each research participant's experience under one condition (treatment 1 ) is then able to be compared with the research participant's behaviour under another condition (treatment 2). The results of this study should be viewed with some degree of caution and requires further replication-particularly considering inclusion in the future studies undertaken in 'theatre' with suitable beneficiary participants.

Working with psychological trauma involves adherence to the principle of non-maleficence-an obligation not to inflict harm on others. Placing beneficiaries in a position where the option is either to 'reveal' their trauma experiences or face potential 'discharge' from the treatment centres puts the beneficiary in an invidious position. For the trauma therapists to be trained in B2T, most found this enlightening and self-empowering - they gained a tool which not only helped them in regard to their own experiences, but they discovered how they as therapist could use this same tool with their traumatised clients. B2T empowers genuine choice for beneficiaries and at the same time equips trauma therapists with more options. EMDR Therapy is now being widely practiced within the Jiyan Foundation-interestingly, 40\% of the clinical sessions used with beneficiaries involve using B2T demonstrating its clinical relevance and utility.

It is also important to provide a context surrounding the environment within which the research project was carried out. Undertaking 'in theatre' research, particularly during times when conflict is still operational presents significant challenges for both researchers and clinicians-this was certainly the case for this research project. During the period of the research study, the situation in Northern Iraq continued to be volatile-ISIL were active and presented a real threat to the region, and beyond. All the research participants that took part of this study were fundamentally immersed in this reality. They were 'living the conflict' as a real-life experience: contemporaneous to the research period. During one of the training sessions, the 'Operation to liberate Mosul' commenced-the consequences of which caused significant concern and anxiety to all the research participants, but also their families, loved ones, colleagues and wider community. The political situation was also precarious with tensions between the Kurdistan Regional Government and the Federal Government in Bagdad-this resulted in closure of the international airport at Erbil, Northern Iraq. This presented a major challenge to the research project which in the grand scheme of things seemed insignificant in comparison to what was actually happening in the region at the time. However, these are some of the realities of undertaking research in conflict zones. This research project would not have been possible if not for the incredible support of our partners at the Jiyan Foundation in the Kurdistan Region of Northern Iraq.

\section{Conclusion}

As indicated earlier, estimates regarding the prevalence of PTSD in Northern Iraq are approximately $60 \%$. The need for empirically supported psychological treatment interventions and trauma capacity building is therefore essential for the region. Trauma Therapy works best when it is adapted to the needs of the client, rather than making the client 'fit' a particular model and paradigm. Effective trauma treatment needs not only to be capable of adapting to the client, it must also adapt to both the context and culture within which such treatment will be used. Mindful of these aspects, this was the primary motivation for carrying out this study. The trauma inflicted on the Yezidi population and the wider community is too important to go un-addressed. The study suggests potential treatment benefits from using EMDR Therapy, and in particular the Blind 2 Therapist Protocol.

There are distinct advantages in using the EMDR Therapy B2T Protocol. In the first instance, it has great potential in addressing shame-based traumas and those traumas that are fuelled by fear of retribution, reprisal and revenge. These aspects are particularly relevant to major conflict zones throughout the world. Secondly, it offers greater cultural and linguistic opportunities by being more flexible and accommodating than other more 'exposure-based' trauma treatment interventions. Thirdly, by processing trauma memories using $\mathrm{B} 2 \mathrm{~T}$, there are many levels of benefit: there is positive impact for the client, their partners, family and the wider community, wherein it assists with challenging stigma. A fourth benefit of B2T is its potential benefits for reducing secondary and vicarious trauma in both therapists and translators. All four aspects need further research investigation and consideration. 
To date, the Yezidi remains a highly traumatised and marginalised population that has been subjected to frequent acts of genocide over many centuries. This study provides a platform and context for further research and development; it demonstrates that B2T is an effective, safe, efficient and relevant protocol when used with Yezidi survivors. Ascertaining approaches that have potential to expand the range of trauma that can be successfully targeted should be welcomed, as any expansion can further equip therapists in the goal of alleviating the global burden of psychological trauma.

'Words have potential to wound and heal - words unspoken continues the pain unabated'.

\begin{abstract}
Abbreviations
APA: American Psychiatric Association; B2T: Blind 2 Therapist Protocol; DSM: Diagnostic and Statistics Manual of Mental Disorders; EMDR: Eye Movement Desensitisation and Reprocessing Therapy; ICD: International Classification of Diseases; ISIL: Islamic State of Iraq and the Levant; ISTSS: International Society for Traumatic Stress Studies; LMIC: Low- and middle-income countries; NC: Negative cognition; NGO: Non-governmental organisation; PC: Positive cognition; PTSD: Post-traumatic stress disorder; SP: Standard Protocol; STD: Standard deviation; SUD: Subjective unit of disturbance; VOC: Validity of cognition; HO: World Health Organization
\end{abstract}

\section{Acknowledgements}

We would like to acknowledge Terres des Hommes (Germany) for their support with this project. In addition, we would like to thank Rolf Carriere, Clare Blenkinsop, Paul Keenan and Lynn Keenan from the Global Initiative for Stress \& Trauma Treatment (Geneva); Tuba Akyuz and Asena Yurtserver from DBE Institute for Behavioural Studies (Istanbul) and EMDR Turkey; Jacky Smith and Heather Cuffe from EMDR UK \& Ireland; Pari Ibrahim and David Sklar from the Free Yezidi Foundation; and all our colleagues at Jiyan Foundation for Human Rights and Torture in Northern Iraq. Without this support, such a study would not have been possible.

\section{Authors' contributions}

DF analysed, interpreted and synthesised the primary data and was also the primary author of the manuscript. MK, AdJ and PM reviewed the research findings and did the primary editing of the paper. PB, HM, SH and CM read and edited the final manuscript. The author(s) read and approved the final manuscript.

\section{Funding}

No financial of other material support was received for this work.

\section{Availability of data and materials}

All data and materials used within the undertaking of this study are available from the primary author and is held on a double password-protected computer at the University of Worcester (UK) in compliance with the European Union General Data Protection Regulation (2018)

\section{Competing interests}

The authors declare that they have no competing interests.

\section{Author details}

${ }^{1}$ University of Worcester (UK), Worcester, UK. ${ }^{2}$ Trauma Aid Germany, Duisburg, Germany. ${ }^{3}$ Northern Hub for Veteran and Military Families' Research, Newcastle upon Tyne, UK. ${ }^{4}$ British Army Infantry Training Centre, Northumbria University (UK), Newcastle upon Tyne, UK. ${ }^{5}$ Academic Centre for Dentistry Amsterdam (ACTA), University of Amsterdam and Vrije Universiteit Amsterdam, Amsterdam, Netherlands. ${ }^{6}$ PSYTREC, Bilthoven, Netherlands. ${ }^{7}$ Salford University, Manchester, UK. ${ }^{8}$ Queen's University, Belfast, UK. ${ }^{9}$ Faculty of Life and Health Sciences, School of Nursing, Ulster University, Magee Campus, Derry, UK. ${ }^{10}$ Mirabilis Health, Glengormley, UK. ${ }^{11}$ Jiyan Foundation for Human Rights and Torture, Sulaymaniyah, Iraq. ${ }^{12}$ EMDR UK \& Ireland Association, Swindon, UK.
Received: 15 May 2019 Accepted: 23 March 2020

Published online: 27 April 2020

\section{References}

Adúriz ME, Bluthgen C, Knopfler C (2009) Helping child flood victims using group EMDR intervention in Argentina: treatment outcome and gender differences. Int J Stress Manag 16(2):138

Ahmad, S. (2016) Jiyan Foundation for Human Rights Annual Report 2015/2016 https:/www.jiyan-foundation.org/images/pdf/jiyan_foundation_annual_ report1516.pdf (page accessed 27-04-2019)

American Psychiatric Association (2013) In: American Psychiatric Pub (ed) Diagnostic and statistical manual of mental disorders (DSM- $5^{\oplus}$ )

Arnberg FK, Johannesson KB, Michel PO (2013) Prevalence and duration of PTSD in survivors 6 years after a natural disaster. J Anxiety Dis 27(3):347-352

Bisson Jl, Berliner L, Cloitre M, Forbes D, Jensen TK, Lewis C et al (2019) The international society for traumatic stress studies new guidelines for the prevention and treatment of posttraumatic stress disorder: methodology and development process. J Traum Stress 32(4):475-483

Blore DC (1997) Use of EMDR to treat morbid jealousy: a case study. Br J Nursing 6(17):984-988

Blore DC, Holmshaw EM, Swift A, Standart S, Fish DM (2013) The development and uses of the "blind to therapist" EMDR protocol. J EMDR Prac Res 7(2):95

Blore DC, Holmshaw M (2009) EMDR "blind to therapist protocol.". Eye movement desensitization and reprocessing: EMDR scripted protocols basic and special situations, pp 233-240

Brown LA, Belli GM, Asnaani A, Foa EB (2019) A review of the role of negative cognitions about oneself, others, and the world in the treatment of PTSD. Cog Ther Res 43(1):143-173

Bunting BP, Murphy SD, O'neill SM, Ferry FR (2012) Lifetime prevalence of mental health disorders and delay in treatment following initial onset: evidence from the Northern Ireland Study of Health and Stress. Psychol Med 42(8): $1727-1739$

Byman D (2016) Understanding the Islamic state-a review essay. Int Security 40(4):127-165

Carriere RC (2014) Scaling up what works: using EMDR to help confront the world's burden of traumatic stress. J EMDR Prac Res 8(4):187

Centonze D, Siracusano A, Calabresi P, Bernardi G (2005) Removing pathogenic memories. Mol Neurobiol 32(2):123-132

Ceri V, Özlü-Erkilic Z, Özer Ü, Yalcin M, Popow C, Akkaya-Kalayci T (2016) Psychiatric symptoms and disorders among Yazidi children and adolescents immediately after forced migration following ISIS attacks. Neuropsychiatrie 30(3):145-150

Cetorelli V, Sasson I, Shabila N, Burnham G (2017) Mortality and kidnapping estimates for the Yazidi population in the area of Mount Sinjar, Iraq, in August 2014: A retrospective household survey. PLoS Med 14(5):e1002297 https://doi.org/10.1371/journal.pmed.1002297

Chessen CE, Comtois KA, Landes SJ (2011) Untreated posttraumatic stress among persons with severe mental illness despite marked trauma and symptomatology. Psychiatric Serv 62(10):1201-1206

Courtois CA, Ford JD (2009) Treating complex traumatic stress disorders: an evidence-based guide. Guilford Press, New York

Dakhil V, Zammit Borda A, Murray AR (2017) 'Calling ISIL atrocities against the Yezidis by their rightful name': do they constitute the crime of genocide? Human Rights Law Review 17(2):261-283

De Jongh A, Ernst R, Marques L, Hornsveld H (2013) The impact of eye movements and tones on disturbing memories of patients with PTSD and other mental disorders. J Behav Ther Exp Psychiatry 44:447-483

Eichfeld C, Farrell D, Mattheß M, Bumke P, Sodemann U, Ean N, Mattheß H (2019). Trauma stabilisation as a sole treatment intervention for post-traumatic stress disorder in Southeast Asia. Psychiatr Q 90(1), 63-88.

Farhood L, Dimassi H, Lehtinen T (2006) Exposure to war-related traumatic events, prevalence of PTSD, and general psychiatric morbidity in a civilian population from southern Lebanon. J Transcult Nurs 17(4):333-340

Farhood LF, Dimassi H (2012) Prevalence and predictors for post-traumatic stress disorder, depression and general health in a population from six villages in South Lebanon. Soc Psychiatry Psychiatric Epidemiol 47(4):639-649

Farrell D (2014) Developing EMDR therapy in Pakistan as part of a humanitarian endeavour. J EMDR Prac Res 8(4):233-239

Farrell D (2018) EMDR therapy in the treatment of a Hillsborough survivor with post-traumatic stress disorder. Journal of Personal Injury Law (JPIL), Issue 2, 2018 
Farrell D, Keenan P (2013) Participants' experiences of EMDR training. J EMDR Prac Res 7(1):2-16

Farrell D, Reid K (2019) 6 EMDR therapy with a head and neck cancer client group. Eye Movement Desensitization and Reprocessing (EMDR) Therapy Scripted Protocols and Summary Sheets: Treating Trauma in Somatic and Medical Related Conditions, p 253

Farrell DP (2016a) Trans-generational trauma and EMDR therapy, Winter edn. BACP Journal - Private Practice

Farrell DP (2016b) Refugee populations: narratives from the Yezidi. Keynote address presented 19th June 2016 EMDR Europe Conference, Den Hague

Farrell DP, Keenan PS, Ali MW, Bilal S, Tareen SM, Keenan L, Rana MH (2011) Training Pakistani mental health workers in EMDR in the aftermath of the 2005 earthquake in Northern Pakistan. Counsell Psychol Quart 24(2):127-137

Fernandez I, Callerame C, Maslovaric G, Wheeler K (2014) EMDR Europe humanitarian programs: development, current status, and future challenges. J EMDR Prac Res 8(4):215-224

Gelbach R, Davis K (2007) Disaster response: EMDR and family systems therapy under communitywide stress. Handbook of EMDR and family therapy processes, 387-406.

Hasanović M, Morgan S, Oakley S, Richman A, Pajević I Šabanović Š (2016) EMDR training for Bosnia-Herzegovina mental health workers resulted with the founding of Bosnia-Herezegovina EMDR association, which became a full member of EMDR Europe in 2015. European Psychiatry 33:S694

Hase M, Balmaceda UM, Ostacoli L, Liebermann P, Hofmann A (2017) The AIP model of EMDR therapy and pathogenic memories. Front Psychol 8:1578

International Society for Traumatic Stress Studies. ISTSS prevention and treatment guidelines (2018). Retrieved from https://www.istss.org/treating-trauma/newistss-prevention-and-treatment-guidelines.aspx: Google Scholar

Jarero I, Artigas L, Montero M, Lena L (2008) The EMDR integrative group treatment protocol: application with child victims of a mass disaster. J EMDR Prac Res 2(2):97

Kemmis S, McTaggart R (1988) Action research-some ideas from the action research planner, ed. Deakin University

Kilpatrick DG, Resnick HS, Milanak ME, Miller MW, Keyes KM, Friedman MJ (2013) National estimates of exposure to traumatic events and PTSD prevalence using DSM-IV and DSM-5 criteria. J Traum Stress 26(5):537-547

Konuk E, Zat Z (2015) Humanitarian programs and interventions in Turkey. J EMDR Prac Res 9(2):106-113

Lobo MA, Moeyaert M, Cunha AB, Babik I (2017) Single-case design, analysis, and quality assessment for intervention research. J Neurologic Phys Ther 41(3):187

Mattheß C, Farrell D, Mattheß M, Bumke P, Sodemann U, Mattheß H (2019) The therapeutic value of trauma stabilisation in the treatment of post-traumatic stress disorder-a Southeast Asian study. Asian J Psychiatry

Maxfield L (2014) Commemorating EMDR's 25th anniversary by highlighting EMDR humanitarian projects. J EMDR Prac Res 8(4):179

McKnight PE, Najab J (2010) Mann-Whitney U test. Corsini Encyclopedia Psychol:1-1

Mehrotra S (2014) Humanitarian projects and growth of EMDR therapy in Asia. J EMDR Prac Res 8(4):252-259

Mohammadi D (2016) Help for Yazidi survivors of sexual violence. Lancet Psychiatry 3(5):409-410

Naseh M, Macgowan MJ, Wagner EF, Abtahi Z, Potocky M, Stuart PH (2019) Cultural adaptations in psychosocial interventions for post-traumatic stress disorder among refugees: a systematic review. J Ethnic Cult Div Social Work 28(1):76-97

Nicolaus P, Yuce S (2017) Sex-slavery: one aspect of the Yezidi genocide. Iran Caucasus 21(2):196-229

Priebe S, Matanov A, Janković Gavrilović J, McCrone P, Ljubotina D, Knežević G et al (2009) Consequences of untreated posttraumatic stress disorder following war in former Yugoslavia: morbidity, subjective quality of life, and care costs. Croatian Med J 50(5):465-475

Qouta S, Punamäki RL, El Sarraj E (2003) Prevalence and determinants of PTSD among Palestinian children exposed to military violence. Eur Child Ado Psychiatry 12(6):265-272

Shapiro E (2012) EMDR and early psychological intervention following trauma. Eur Rev Appl Psychol 62(4):241-251

Shapiro F (1989) Efficacy of the eye movement desensitization procedure in the treatment of traumatic memories. J Traum Stress Stud 2:199-223

Shapiro F (1995) EMDR: basic principles, protocols, and procedures. Guilford, New York

Shapiro F (2001) Eye movement desensitization and reprocessing: basic principles. Prot Proc 2
Shapiro F (2014a) The role of eye movement desensitization and reprocessing (EMDR) therapy in medicine: addressing the psychological and physical symptoms stemming from adverse life experiences. Permanente J 18(1):71

Shapiro F (2014b) EMDR therapy humanitarian assistance programs: treating the psychological, physical, and societal effects of adverse experiences worldwide. J EMDR Prac Res 8(4):181

Shapiro, F., (2016). Clinician's Corner: EMDR therapy. Stress Points: International Society for Traumatic Stress Studies.

Shapiro, F (2018) Definition of EMDR Therapy in https://www.istss.org/ getattachment/Treating-Trauma/New-ISTSS-Prevention-and-TreatmentGuidelines/ISTSS_PreventionTreatmentGuidelines_FNL-March-19-2019.pdf. aspx Page 21. (Accessed 27-04-2019)

Silver SM, Rogers S, Knipe J, Colelli G (2005) EMDR therapy following the 9/11 terrorist attacks: a community-based intervention project in New York City. Int J Stress Manag 12(1):29

Stringer ET (2013) Action research. Sage publications

Tekin A, Karadağ H, Süleymanoğlu M, Tekin M, Kayran Y, Alpak G, Şar V (2016) Prevalence and gender differences in symptomatology of posttraumatic stress disorder and depression among Iraqi Yazidis displaced into Turkey. Eur J Psychotraumatol 7:28556

Tol WA, Barbui C, van Ommeren M (2013) Management of acute stress, PTSD and bereavement: WHO recommendations. J Am Med Assoc 310(5):477-447

Van der Kolk BA (2015) The body keeps the score: brain, mind, and body in the healing of trauma. Penguin Books

Wolpe J, Lazarus AA (1966) Behaviour therapy techniques: a guide to the treatment of neuroses

Womersley G, Arikut-Treece Y (2019) Collective trauma among displaced populations in Northern Iraq: a case study evaluating the therapeutic interventions of the Free Yezidi Foundation. Intervention 17(1):3

World Health Organization (2013) Guidelines for the management of conditions that are specifically related to stress. World Health Organization

World Health Organization. (2019). International statistical classification of diseases and related health problems (11th Revision). Retrieved from https:// icd.who.int/browse11/l-m/en

\section{Publisher's Note}

Springer Nature remains neutral with regard to jurisdictional claims in published maps and institutional affiliations.

\section{Submit your manuscript to a SpringerOpen ${ }^{\circ}$ journal and benefit from:}

- Convenient online submission

- Rigorous peer review

- Open access: articles freely available online

- High visibility within the field

- Retaining the copyright to your article

Submit your next manuscript at $\boldsymbol{\nabla}$ springeropen.com 